\title{
Lakatos's Research Program and the thought of the Islamic Republic
}

\author{
Ali Alihosseini $^{1} \&$ Hamidreza Keshavarz ${ }^{1}$ \\ ${ }^{1}$ University of Isfahan, Iran \\ Correspondence: Hamidreza keshavarz, Faculty of Economy \& Administrative Sciences, Department of Law and \\ Political Sciences, University of Isfahan, Isfahan, Iran
}

Received: December 10, 2015

Accepted: December 25, 2015

Online Published: January 13, 2016

doi:10.5539/mas.v10n3p57

URL: http://dx.doi.org/10.5539/mas.v10n3p57

\begin{abstract}
In the volatile history of science, we come across a series of theories and methods, each of which has emerged and has been used at some point and has been replaced later by another method. These multiple methods and theories have each caused science and scientific knowledge to advance one step forward. One of these theories is Imre Lakatos's research program which, though a theory often considered in the analysis of the trends of the empirical sciences, given the general principles and the dominant spirit of this theory, it can be also used to study other intellectual currents. Lakatos believes that any theory is a research program that is composed of two parts: a hard core and a protective belt. The hard core is the basis and foundation of every thought and theory .To protect the main theory and to protect it against changes, there exist the protective belts that are somehow a supplement to the core of the theory .According to Lakatos, the progressive or retrogressive nature of a research program depends on the ability and acceptability of the auxiliary hypotheses which serve to protect the hard core. Thus, a research program can be progressive and dynamic if it causes new theories which bring about new predictions by modifying the protective belt. This article has considered the notion of the Islamic Republic of Iran as a research program. In this regard, this study is an attempt to determine the functions of 'expediency' in the Islamic Republic using an impression of the concept of 'expediency' which is similar to the protective belt by considering Islam as a hard core and as a resistant framework. This article is also an attempt to emphasize the point that, in the Islamic Republic, the concept of 'expediency' has the same function which is noted as the protective belt in Lakatos's view. Therefore, using the notion of 'interest' by the advocates of the hard core is an attempt made to prevent the rejection of the hard core and pave the way for the development and change in Islam as an efficient religion.
\end{abstract}

Keywords: Lakatos, hard core, protective belt, Islam, expediency

\section{Introduction}

The fact that words play a central role in shaping the attitudes and even the evaluation of policies due to the transmission of mental meanings has led the researchers to be very sensitive to the conceptual world of the words and even think that the power equations are influenced by the word games. This subject becomes even more significant when the considered word is changed into the practical and theoretical guide of a theory by shaping a particular theory. This condition has occurred respecting the 'interest' and, for the same reason, we witness the formation of various intellectual streams with respect to the manner in which they approach this theory. The word 'expediency' which is a concept used in the political Islamic jurisprudence has a significant role in the area of Islamic thought. This concept has always been posed throughout the history in the Shia and Sunni political jurisprudence. The concept of 'expediency' is one of the concepts which have been studied and investigated in great detail in the area of political thought. This notion is one of the most important pillars and foundations of decision-making which is dominant in the various dimensions of the human community. Throughout the history of Islam, many thinkers have always proposed their theories concerning the 'expediency'. The Shia religious scholars have written beneficial points in this regard on various occasions and within religious enquiries, though they have not spoken about it in a peculiar aspect and have not explored its varied dimensions. With the formation of the Islamic Revolution of Iran led by Imam Khomeini, a new aspect was added to this concept by Imam Khomeini and he transmitted it from the realm of religious enquiry into the realm of politics and society.

For political affairs, thanks to the late Imam's creativity, this concept has been given a special place in the historic order for the formation of the Expediency Discernment Council of the System for the Islamic Republic 
of Iran. By this order, he revealed the new meaning of this concept and operationalized this concept more than ever within the areas of politics, government and society. The welfare and interest of the system are among the significant affairs and sometimes negligence in this regard leads to the defeat of the adorable Islam (The Sahifeh of Imam, vol. 20, p. 176). The emphasis on expediency and is very tangible in Imam's words. Despite this emphasis and the awareness of the thinkers regarding the importance and effect of 'expediency' in preserving Islam and the Islamic regime, most of the studies done on this subject are merely dedicated to emphasizing the subject and are devoid of its pathology. In this research study, in addition to studying and exploring the concept of 'expediency', we take steps to answer the question about what role and function this concept plays in the Islamic Republic of Iran.

\section{The Theoretical Framework}

According to the view advocated by Imre Lakatos in the form of research program, any theory consists of two main parts: the hard core and the protective belt. In Lakatos's view, each research program is known by its hard core. The hard core or the framework consists of very general theoretical hypotheses that form the basis of a scientific theory (Lakatos, 1978, p. 48). This hard core has basic hypotheses which form the central nucleus of a scientific theory and moderating or abandoning them means alienation from a theory and entering another theory (Mohammadrezaee \& Biabanaki, 2010, p. 33). This framework on which the development and the change of a research program depend becomes irrefutable by the methodological decision of its advocates (Chalmers, 2008, p. 98). By establishing the main core for the theory, Lakatos is trying to determine the continuity in science using general propositions (Lakatos, 1978, p. 110). The hard core as the theoretical hypotheses is the basis and foundation of Lakatos's research programs which are unchangeable and any scientist who enters this research program accepts it as the main rudiment of his or her work and the other activities are in line with protecting, analyzing and describing it further. The scientist has a place in this research program as long as he accepts the hard core and the main framework of the theory and by refuting or rejecting it, he is excluded from the research program. Therefore, any thinker who moderates the hard core or the framework has stepped out of the research program (Chalmers, 2008, p. 99).

The protective belt is also a combination of auxiliary hypotheses which are sacrificed for the survival of the program in cases when the main hypotheses are jeopardized in the hard core of the research program (Masudi, 2007, p. 329). Lakatos believes that the protective belts consist of various auxiliary hypotheses which solidly protect the hard core against any refutation (Lakatos, 1996, p. 110). He establishes the protective belts that somehow complete the hard core of the theory in order to guard it against changes. This belt proposes the necessary information and explanations about the main core. He attempts to take actions to remove the faults and problems of the main core by posing the issue of protective belts and, if possible, avoid its changes by more processing and precision. Lakatos associates the degree to which a research program is retrogressive or progressive with the plausibility and capacity of the auxiliary hypotheses. If a research program creates theories which bring about new prediction by creating changes in its protective belts, then this research program is theoretically progressive and if some of these hypotheses are strengthened or confirmed, this program will be practically progressive as well. However, if the new changes and distinctions that the new theory has in comparison with the previous theories are such that they only prevent the refutation of the hard core and do not result in any new predictions whatsoever, then the new program is a declining program (Mohammadrezaee and Biabanaki, 2010, p. 29).

The research program proposed by Lakatos provides guidelines in a positive and negative way. The negative guideline of a program includes the condition that the basic assumptions of that program and its framework must not be abandoned, falsified, or moderated (Chalmers, 2008, p. 98) and this is an instruction to avoid the rearrangement of the main and undeniable core of the program (Chernov, 2009, p. 211). Here, protecting and preserving the framework of the main program is deemed pivotal and any violation means abandoning the research program. The negative solutions consist of guidelines and instructions which generally have a negative aspect and explain how the research program must be adhered to in order to avoid the damages to the hard core and this often leads to the addition of hypotheses commensurate with the same solutions (Masudi, 2007, p. 385). The negative guideline accepts some changes and reforms in the protective belts that are in line with the supplementation and strengthening of the main core and the principle is that those hypotheses that are contradictory and heterogeneous respecting the program framework should not be formed or accepted as they lead to further contradictions.

The positive guidelines are positive instructions and regulations that tell the researcher how to behave and what points to follow which may contribute to the protection and the progress of his or her program (Masudi, 2007, $\mathrm{p}$. 321). According to Lakatos, the positive guideline consists of a combination of demands or some developed 
points which refer to the manner in which the refutable variables of a research program can be developed or modified (Chalmers, 2008, p. 100). The positive guideline is used to complete the framework and leads to the addition of hypotheses to the research program and helps the researcher to choose auxiliary and logical hypotheses which lend support to the progress of the research program. Generally, the positive and negative guidelines which are used to complete and expand the research program and prevent the distortion of the main core provide the opportunity for suggesting solutions to the problems if there is some difficulty in the progress of the program.

Given the Lakatos's theory, two important points can be inferred: first, each theory composes of two main parts which were mentioned earlier and, second, the Lakatos's theory holds two recommendations for the followers of this thought. One is the prevention of any doubts and refutations about the hard core, which is based on Lakatos's thought, and this important duty is done by the methodological decisions made by the followers and the other is the attempt made to develop and modify the hard core for the survival of a theory. The current study will not adapt the whole of the contents of the Lakatos's thought to the notions of the Islamic Republic. What is of great importance in this text is the identification of the protective belt and the hard core of the thought of the Islamic Republic which is going to be addressed with regard to the expediency observed in the form of government orders by the leaders. Accordingly, although the author claims that this interpretation of the concept of 'expediency' provides the ground for the progressiveness and the dynamicity of the thought of the Islamic Republic, we leave the study of its mechanism for another time.

The first principle: The expediency and the protective belt

The word "expediency" is the English equivalent for the Arabic word "Maslahat" which is among the words used in the political and Islamic jurisprudence and the etymologists believe that it has been derived from the Arabic root "Salaha" which is used in contrast to "Fasad" and it has been interpreted as the antonym for corruption (Alshartuti, 1983, p. 656). This word is synonymous with the word "interest" and as interpreted by Ghazali in Almostasfa, it is the closest equivalent for the word interest from an etymological point of view (Ghazali, 1885, p. 140).The word "interest" has an etymological rhythm with the words "profit' (Arabic: Manfa'at) as an infinitive root meaning the right and proper thing (Arabic: Salah) while the word as an infinitive denotes 'interest' and is in this case an antonym for the word "corruption" (Eftekhari, 2011, p. 20). This concept shows a variety of interests which all have 'profit' in common.In Persian, there have been many meanings considered for 'interest' and all have a common etymological root such as good, pleasant, pleasure, interest, profit, bounty, wisdom, and cause (Eftekhari, 2011, p. 20). Given the conceptual demarcations that exist in the above words, the precise synonymy of the words is contradictory but such details are not held within the scope of this text. In this article, we mostly emphasize on the meaning of the concept of 'interest' as a term.

\section{Expediency as a Term}

The term 'expediency' - commensurate with the concept of interest - means: The interest that the wise ruler has desired for his creatures. These interests include protecting the religion, life, reason, children and possessions, based on priority (RamazanAlbuti, 1992, p. 27). The basis of this definition given by Albuti is the classification provided by Gazali:

"What we mean by expediency is protecting one's religion, life, reason, children and possessions and there is an interestin each of the five principles. Therefore, whatever may lead to the achievement of these five principlesare called 'expediency' and what is not is called 'evil'. The avoidance of such an interest points to another expediency". (Ghazali, 1885, p. 14).

Ghazali associates the definition of 'expediency' with the goals of the ruler in protecting religion, reason, children and possessions and he has viewed whatever lends support to the above-mentioned items as 'expediency'. In his opinion, interest is the same thing as the intentions of Sharia and is not considered a separate principle. RamazanAlbuti, the contemporary scholar and expert, follows Ghazali in believing that:

"Expediency as used by the religious scholars might be defined as: an interest that the wise ruler has considered for his people and includes the following items respectively: religion, life, children (generation), and their possessions." (RamazanAlbuti, 1992, p. 27).

\section{Governmental Decree}

There have been some attempts by the thinkers for investigating the kinds of decrees as a term and the rules regulating the government decrees and how they differ from the primary and secondary decrees and they fall out of the scope of the current study (Note 1). With regard to the government decree, many definitions have also been provided and we can point to the one given by Allameh Tabatabaee: 
"Government decrees are the decisions that the supreme leader selects regarding the compatibility with the Sharia laws based on temporal expediency and establishes some rules and performs them accordingly. The afore-mentioned regulations are compulsory and are credible like Sharia with the difference that the divine rules are constant and unchangeable and the legislated rules are changeable and are influenced by an expediency which has created them in stability and constancy and because human life is constantly changing and evolving, these regulations will naturally change and are replaced by better regulations." (Tabatabee, 1963, p. 83).

The government decree is defined by Imam Khomeini as follows:

"The decrees that the leader of the society announces with regard to his leadership and power and they differ from the decrees announced as the divine orders and demands." (Alrasael, 1989, p. 120).

Hence, in sum, it can be said about the government decree that they are the orders and decrees announced by the Islamic ruler based on religious and rational regulations and the expediency of the public for performing the divine decrees and limits and in order to manage the Islamic community according to necessities of the time (Adyani, 2011, p. 76).

Examples of the government decrees given by Imam Khomeini:

1-The decree for the formation of the Revolution Council

In a decree for the establishment of the Revolution Council in 11/Feb/1979, Imam Khomeini accosted the Islamic nation of Iran:

Based on the legitimate right and based on the vote of confidence of the vast majority of the people of Iran which have been invested in me, a council called the Islamic Revolution Council consisting of qualified, reliable, and committed Muslims will be temporarily determined to perform duties in line with the realization of the Islamic goals of the nation (The Sahifeh of Imam, vol. 20, 176).

2-Appointing the late Mehdi Bazargan as the Prime Minister of Iran:

He announced this appointment based on the power that the qualified theologian has in the age of the absence of the Imam over the Muslims and the society. Imam Khomeini declared in regard to the decree appointing Mehdi Bazargan:

As recommended by the Revolution Council based on the legitimate and religious right for the vote of the vast majority of the people of Iran which has been expressed to the leader in huge crowds and widespread and multiple demonstrations all over Iran, I authorize you to form the government without considering party relations and independently of any particular group...(The Sahifeh of Imam, vol. 6, p. 54). In the same way, he declared elsewhere: I must note another point and that is I appointed him (Mehdi Bazargan), I am a person who appointed him according to the authority invested in me by the wise ruler and he who is appointed by me must be obeyed...(The Sahifeh of Imam, vol. 54).

3-The decree of the dismissal of Ayatollah Montazeri as the deputy leader:

Imam Khomeini announced the decree of the dismissal of Ayatollah Montazeri in 07/Ap/1989 and said:

With greetings and the wish for your success. As you have written, leading the Islamic Republic is a hard task and a heavy and risky responsibility that asks for tolerance beyond your power. For the same reason, both you and I opposed your appointment from the very beginning but as the Council of Experts had concluded this, I did not want to interfere in their legal affairs. I sincerely express my gratitude for the fact that you have declared that you are not prepared to take the position of the deputy leader. Everyone knows that you have been the outcome of my life and I am very fond of you. To avoid the previous mistakes, I seriously advise you not to accompany indecent people and do not interact with the dissidents of the regime who pretend to be interested in Islam and the Islamic republic....(The Sahifeh of Imam, vol. 6, p. 324)

The Supreme Leader and the point of expediency in announcing the government decree:

1-Bill amending the law on the press

In 2000, the Judiciary opposed the press that had violated the law and stopped some of them. This act of the Judiciary caused some of the parliament members in the first days of the sixth parliament period to introduce a program indicating an urgency in the parliament and, in fact, they were trying to increase the freedom of the press. In such a condition when it seemed that the newspapers had been turned into the enemy's base, the Supreme Leader of the Revolution wrote to the chief of the parliament and the members of the parliament considering the welfare and expediency of the regime and the country and said that:

In the name of God 
Dear Mr. Karoubi, the respectable speaker of the parliament, and the respectable members of the parliament

With greetings,

The press and the newspapers of the country construct and direct the public opinion and the people's endeavors and will. If the enemies of Islam and the Revolution and the Islamic Regime take over the press or penetrate it, a great danger threatens the security, the unity and the faith of the people and I do not think that my being silent in this regard can be justified. The present law has been effective to some degree in preventing this great trouble and changing it into what has been suggested in the commission of the parliament is not in line with the expediency of the regime and the country.

With greeting and peace,

Seyyed Ali Khamenei

$05 / \mathrm{Aug} / 2000$

\section{2-Qualifying Moeen and MehrAlizadeh in the ninth presidential elections}

Disqualifying these individuals caused the students' tensions and protests in the society. Under those circumstances, in a letter to the leader, the chief of the Islamic parliament asked that the Guardian Council should revise the qualification of the presidential candidates and, following this event, considering the expediency of the regime, the Supreme Leader wrote a letter to the head of the Guardian Council saying that:

To Ayatollah Janati, the chief of the Guardian Council

With greetings and gratitude for the services provided by the respected council in an attempt to qualify the presidential candidates for the ninth period and observing the legal laws in this affair, as it is desirable to allow all the people from different viewpoints to have the opportunity to be present in the great test of the elections, it seems that you should revise the disqualification of Dr. Mostafa Moeen and Mehr Alizadeh.

Following the letter of the Supreme Leader to the Guardian Council, this council qualified the afore-mentioned individuals in a letter to the Supreme Leader. (Adyani,(B), 2011, p. 80-82)

3-Canceling the appointment of Esfandyar Rahim Masha'ee as the ninth vice president:

Mr. Mashaee was introduced as the vice president in Tir 27 1388. This appointment caused some tensions and oppositions among the dissidents and even the proponents of the president. Following the outbreak of these tensions, observing the expediency of the country and the government, the Supreme Leader ordered the president to dismiss him in a letter. He wrote in the letter that:

In the name of God

Dr. Ahmadinejad, the respected president of the Islamic Republic of Iran

With greetings,

The appointment of Esfandyar Rahim Masahee as vice president is against your own interest and the expediency of the government and causes opposition and frustration among your advocates. It is necessary to declare his appointment null and void.

Seyyed Ali Khamenei

18/Jul/2009 (Note 2).

Two points should be noted in connection with the above decrees.

The first point: based on the definitions provided for the government decrees by Allameh Tabatabaee and Imam Khomeini, the issuance of these decrees on the part of the ruler of the Islamic country is due to the expediency. While indicating the features of the government decree, Savarsafli describes the interest implied by a government decree in the following way. He believes that:

1-The government decree is indeed an optional act of the Islamic ruler which generally clarifies the duty of the citizens and it is mandatory that everyone obey it.

2-Sometimes such a decree is issued when there is a conflict among the rights of individuals. In this case, the ruler's decree puts an end to the hostility and conflicts. Also, the leader can intervene in some cases such as demanding silence regarding some files or punishing or pardoning a criminal based on the expediency he has identified.

3-The subject of the decree of the ruler is mostly partial and is associated with a particular event such as the tobacco ban declared by Mirza Shirazi. 
4-Disobeying the ruler's decree is not allowed for anyone as it results in tension and chaos in the management of the community and this is opposed to the interest thought by the wise ruler.

5-Since the government decree is issued by the Muslims' leader and based on the welfare and the expediencies of the nation, this decree is not obligatory at other times in case the expediency change even if they are issued by an Imam (Savarsafli, 2000, p. 26).

The second point: The expediency in the afore-mentioned cases and particularly in the government decrees issued by the Supreme Leader is always used to avoid the damage to a more important totality. The importance of this totality is such that, in order to safeguard it using the principle of expediency and the government decrees, not only the secondary decrees but also the primary decrees can be neglected (Haghighat, 2010, p. 32). Imam Khomeini writes in reply to the letter by the chief of the parliament concerning the urban lands law (20/Aug/1981):

"What is included in the protection of the Islamic Republic System can cause disorders in the system if done or repealed and what is necessary can cause corruption if done or repealed and also what causes difficulties if done or prevented, therefore, by the discretion of the members of the Islamic parliament and by stipulating that it is a temporary allowance so long as the problem exists they are free to ratify and perform thebill while this is no longer the case when the problem is solved."(The Sahifeh of Imam, vol. 15, 188).

About this letter, Eftekhari believes that the importance of protecting the system as the most important duty dictates that the Islamic regime follow a policy that is commensurate with the welfare of the public (Eftekhari, 2011, p. 166). The above-mentioned case and Eftekhari's interpretation perfectly show the instrumental and belt-like function of the concept of expediency so as to protect the more important totality which is in this case the political system of Islam. This point shows that, based on the claim mentioned in the current chapter, expediency in the Islamic Republic has the same function that the protective belt plays in Lakatos's theory.

The second principle: Islam and the hard core

What is significant in the next stage is this question: "this belt-like use of the concept of 'expediency' is used for protecting and safeguarding what entity?" In other words, what is included in the concept of 'expediency' in the Islamic Republic of Iran? To use more plain words, what are the framework and the hard core in response to which the concept of 'expediency' acts as a protective belt? To answer these questions, it is necessary to return to the thought and words of the great architect of the revolution.

Generally speaking, Imam Khomeini has classified the attribute of expediency into five concepts:

A-The expediency of the regime

"You gentlemen must be aware that the expediency of the system is of the important affairs and neglecting it can at times lead to the defeat of the adorable Islam. Today, the Muslim world recognizes the Islamic republic of Iran as a role model for solving the problems." (The Sahifeh of Imam, vol. 20, p. 176).

B-The expediency of the people

"The expediency of the regime and the people are of the important affairs and neglecting them may undermine Islam as understood by the oppressed people of the world in the future and help the American Islam of the oppressors to become victorious supported by billions of dollars through the servants inside and outside the country." (The Sahifeh of Imam, vol. 20, p. 176)

C-The expediency of Islam:

"If, god forbid, I see that sometimes the interest of Islam dictates that I should say something, I do so and I follow that and fear nothing." (The Sahifeh of Imam, vol. 9, p. 219). "In the oil company, there has been a violation of the expediency of the Muslims and Islam or there might be some conspiracies so they must be tackled." (The Sahifeh of Imam, vol. 9, p. 219).

"In performing the affairs, a person and the authorities who are responsible for these affairs must consider what the expediency of Islam is." (The Sahifeh of Imam, vol. 19, p. 225)

D-The expediency of the Muslims

"It is hoped that the gentlemen and the younger generation, given the heavy responsibilities which will be given to them in the future, God willing, and will be responsible for safeguarding Islam and the expediency of the Muslims, try to prepare themselves against this great and huge shelter (The Sahifeh of Imam, vol. 22, p. 60)

E-The expediency of the country: 
"The meaning of the freedom of writing and expression is not that one is free to write against the expediency of one's country or the revolution for which people have paid with their blood, such a freedom is not right" (The Sahifeh of Imam, vol, p. 6, 192). "You should put the future of the country in the hands of those people who do not think of their own expediency before the expediency of the nation" (The Sahifeh of Imam, vol. 11, p. 269).

In line with the determination of the attribute of expediency in the Islamic Republic, Sarami believes that, given the point that the prominent feature of the Islamic rule is the implementation of the decrees and demands of slam in the society, we should search for the attribute of expediency within the four possibilities mentioned below:

\section{1- The Islamic regime}

2- Islam

3- The Muslims

4- The Islamic community (Sarami, 2001, p. 77).

To clearly determine the attribute of expediency in the Islamic Republic, he is of the opinion that:

"The first option is not correct because the issuance of a government decree does not depend on the existence of an Islamic regime and system and there have been also many government decrees throughout the history of Shia without the condition that an Islamic system was established. The government decree could be realized just as the legitimate leadership was established in the Islamic community." (Sarami, 2001, p. 77). While rejecting the second and the third possibility, he incorporates both of them in the fourth possibility and claims that the attribute of expediency lies within the Islamic community (Sarami, 2001, p. 77).

A criticism that can be laid against Sarami's analysis is that he has used ratiocination and has used an outwardly view of the concept of expediency without appeal to the words of the founder of the Islamic Republic. To ascertain the gist and the hard core of the theory of the Islamic Republic for which expediency plays the role of a protective belt, we need a more detailed attention to the thought of Imam Khomeini in addition to a historical investigation.

In 6/Nov/1981, he said in a meeting with the authorities from the Martyr Foundation:

"Today, we are facing all the powers and they plan inside and outside the country to break the revolution and defeat and destroy this Islamic movement and the Islamic Republic and this is a divine duty for all: This is the most important duty that God has which means that the protection of the Islamic Republic is more important than protecting a single person, though he should be the Imam of the era, as Imam will also sacrifice himself for Islam".(The Sahifeh of Imam, vol. 15, 363).

The above case defines the hard core in two phases. What can be seen at first sight is that protecting the Islamic regime has a priority over any other totality in the thought of Imam Khomeini. But when he says later that "even the Imam of the era will sacrifice himself for Islam", this shows at a later stage that protecting the political regime is not a goal in itself but such a regime is dedicated to another totality which is the establishment of Islam. The latest point which is itself a criticism against the thought of those who believe in the proposition that "preserving the regime is the top priority" demonstrates that preserving the system in the Islamic Republic is regarded as an instrument to achieve the objectives of Islamic religion and preserving the regime (Islamic Republic) is not regarded as an end by itself. The explanation is that the Islamic rule is indeed established for providing the rights of the people (such as liberty, and so on), and guiding and educating them in the religious context, and to realize the divine decrees and the aims of religion, it is necessary to form a government and therefore the government is established for the realization of these goals (Taghavi, 1999, p. 92). Now, if such instrumentality (which is the provision of the people's rights, the divine incentive, and guiding and educating the people) in a religious context is removed and if the regime and the system will no longer maintain the rule of divinity, then it is not essential to preserve them any longer (Taghavi, 1999, p. 92). Imam has also expressed the instrumentality of the government thus:

"But they remain until the Judgment Day and the persistence of these kinds of decrees depends on the fact that the authority and rule which performs the regulations and safeguards them can be realized and performing the divine duties is not possible without a government because it causes chaos and, moreover, preserving the Islamic regime is a top priority and chaos and confusion in the affairs of the Muslims have been forbidden.

As it is clear, performing the decrees as long as they remain and the need for the existence of a government to carry them out on the one hand and, dealing the protection of the regime (in a more particular sense), on the other hand, can be viewed by the fact that there might be chaos and disorder in the Muslims' affairs and, thus, the first item is a necessary deed while the second item is a forbidden affair. As one can infer from the words of 
Imam, protecting the regime is not a superior goal by itself but protecting the regime is necessary to carry out the divine decrees and it thus offers a solution. In the same vein, he has other speeches:

"The divine incentive that everything will return to God is more important. And when God sent the prophets, the main reason was not for them to create a regime.... he has sent the prophets to educate and rescue the people...." (The Sahifeh of Imam, vol. 19, p. 255-256). "All the prophets who have come from the dawn of creation to the present time have fought for the right thing and the God's religion and sacrificed themselves." (The Sahifeh of Imam, vol. 19, p. 363).

Of the most important of these fights is of course the establishment of the God's religion. In sum, it can be concluded that the hard core in the theory of the Islamic Republic is Islam and not the political regime inasmuch as the political regime is important as it is established to maintain Islam completely both rationally and based on the thought of the architect of the Islamic Republic.

\section{Conclusion}

Imre Lakatos believes that in a research program any theory consists of the hard core and the protective belt for protecting the core. Likewise, based on this theory, the hard core becomes irrefutable with the help of the protective belt and also the methodological decisions made by the followers of the theory. The current study has considered the thought of the Islamic Republic as a research program to identify the hard core, the protective belt and the transparency of the methodological decisions of its advocates in maintaining the hard core against moderation and damages.

By returning to the thought of Imam Khomeini and also the Supreme Leader and given the issued government decrees in the Islamic Republic by its leaders, it has been demonstrated that Islam is the hard core in the thought of the Islamic Republic and not the regime nor the Islamic community. At the next stage, it was indicated that the protective belt in the thought of the Islamic Republic, which always acts in favor of protecting the hard core, is the notion of expediency. Likewise, and based on the research program provided by Imre Lakatos, the current article claims that this understanding of the notion of interest can provide the constant possibility of progress and dynamicity for the thought of Islamic Republic and studying its mechanism requires another opportunity.

\section{References}

Adyani, S. A. R. (2011). The application of expediency in the Islamic Republic (1). Hasun, 31(A).

Adyani, S. A. R. (2011). The application of expediency in the Islamic Republic (3). Hasun, 33(B).

Alshartuti, S. A. (1983). Aqrab Al-Mavared, Qom, Ayatollah Marashi Library.

Chalmers, A. F. (2008), The Nature of Science, Introduction to Scientology philosophical schools, translated by Saeed Zibakalam, Tehran, research organizations and Humanities Textbooks.

Chernov, Fred (2009), theory and sub-theory in international relations, AlirezaTayeb, Tehran, Reed Publishing.

Eftekhari, A. (2011). Expediency, Tehran, university of imam Sadegh.

Ghazali, M. (1885). Almostasfa men Elm Al-Osul, vol. 2, Qom, Dar-Alzakhaer.

Haghighat, S. S. (2010). The dual role of political and legal expediency. Shia Studies Journal, 32.

Imam, K. (1982). Sahifa, Tehran, Institute for the Publication of Imam Khomeini’s works.

Imam, K. (1982). the books of Imam Khomeini, Tehran, Institute for the Publication of Imam Khomeini's works.

Imam, K. (1989). letters, third edition, Qom, Ismailian.

Imam, K. (2000). Albaye, Tehran, Institute for the Publication of Imam Khomeini's works.

Lakatos, I. (1996). Science and pseudoscience, ShapurEtemad, Tehran, Markaz.

Lakatos, L. (1978). The methodology of Scientific Research Programmes. In J. Worral \& Currie (Eds.) London: Cambridge University Press.

Masudi, J. (2007). Hermeneutics and religious modernism, Qom, Islamic Sciences and Culture Academy.

Mohammadrezaee, M., \& Mehdi, B. (2010). The interaction of science and religion based on the methodology of the Lakatos research program, philosophy of religion, (7).

RamazanAlbuty, M. S. (1992). The regulations of interest in the Islamic Sharia, Beirut, Alresaiyyh institute.

Sarrami, S. A. (2001). State laws and interests, Tehran, NashrObid.

Saversafli, M. E. (2000). The ruling regime in the theoretical and practical life of Imam Khomeini, Tehran, 
Al-Zahra University.

Tabatabai, S. M. (1963). A discussion of the authority of the clergy, Tehran, Inc. publication.

Taghavi, S. M. N. (1999). Government and expediency, Tehran, Amir Kabir.

\section{Notes.}

Note 1. For more study, R. K: Alireza Adyani (2011) the framework of interest in the Islamic republic, Hosun, no. 31.

Note 2. http://farsi.khamenei.ir/message-content?id=7495

\section{Copyrights}

Copyright for this article is retained by the author(s), with first publication rights granted to the journal.

This is an open-access article distributed under the terms and conditions of the Creative Commons Attribution license (http://creativecommons.org/licenses/by/3.0/). 